\title{
A RARE CASE OF CARCINOID TUMOUR PRESENTING AS AN ACUTE INTESTINAL OBSTRUCTION WITH CRYPTORCHIDISM
}

\author{
Charles N.R. \\ Basu A. ${ }^{4}$
}

\author{
Christian L.B. ${ }^{2}$ \\ Sharma $\mathbf{P}^{5}$
}

\author{
Harishchandra B. ${ }^{3}$ \\ Krishnanand G. ${ }^{6}$
}

\section{ABSTRACT:}

A 40 year old man known to have cryptorchidism, presented with acute intestinal obstruction. At laparotomy stricture of the distal ileum, distended small intestine with enlarged multiple mesenteric and pelvic nodes were found. Right hemicolectomy was done and biopsies of mesenteric and pelvic lymph nodes proved the tumour to be malignant carcinoid tumour with metastasis to lymph nodes. Biopsy of the atrophied right testis showed presence of seminal vesicles.

\section{KEY WORDS: carcinoid tumour, obstruction, small intestine, cryptorchidism}

\section{INTRODUCTION:}

Carcinoid tumours are the most common gastrointestinal endocrinal tumours. They constitute $55 \%$ of all the gut endocrinal tumours and $13-$ $34 \%$ of all tumours of the small instestine. The incidence is 1.5 per 100,000 , of the general population $^{1,2}$. Carcinoid tumours may originate from neuro-endocrine cells all along the ${ }^{1,2}$ gastrointestinal tract ${ }^{3}$ About $85 \%$ of these are located in the intestine. They also occure it the lungs ${ }^{4}$, thymus ${ }^{5}$, pancreas, biliary tract, kidneys ${ }^{6}$, ovaries of testis ${ }^{7}$.

The most common location of carcinoid tumours in the gastrointestinal tract is the appendix. Appendiceal carcinoids rarely metastasize. Ileal carcinoids $^{3}$ have the highest propensity to metastasis.

Though the peak incidence ${ }^{1,2}$ is between the $6^{\text {th }}-7^{\text {th }}$ decades, carcinoid tumours can occur from the age of 10 years to 90 years. Gastric carcinoids are frequently silent. If symptomatic, they cause upper abdominal pain or bleeding. Carcinoid tumours are often silent and are found incidentally at laparotomy. Appendicular carcinoids may present as an acute abstructive appendicites.

Carcinoid tumours are slow growing and may be present for years without symptoms. Onethird of these patients have chronic intermittent abdominal pain. Malignant carcinoid tumours ${ }^{3}$ generally induce advanced fibrosis which by kinking of the intestine and fibrous adhesions may cause mechanical obstruction even when the primary tumour is small.

Other symptoms include diarrhoea, upper GI bleeeding, weight loss, intussusception, and a palpable abdominal mass. The most frequent site for hind-gut carcinoid is the rectum. These tumours present with bleeding per rectum. If tumour metastases to the liver, clinical features of carcinoid syndrome will be present.

1. MS. General Surgery, Assistant Professor - Manipal college of Medical Sciences, Pokhara, Nepal.

2. MS. General Surgery, Assistant Professor - Manipal college of Medical Sciences, Pokhara, Nepal.

3. Dip NB (General Surgery), FRCS, Assistant Professor - Manipal College of Medical Sciences, Pokhara, Nepal.

4. MD. Pathology, Assitant Professor - Manipal College of Medical Sciences, Pokhara, Nepal.

5. MS. General Surgery, Lecturer - Manipal College of Medical Sciences, Pokhara, Nepal.

6. MD. Pathology, Associate Professor - Manipal College of Medical Sciences, Pokhara, Nepal.

Address for Correspondence : Dr. Neelam R. Charles, MS General Surgery, Assistant Professor Manipal College of Medical Sciences,

P.O.Box : 155 , Deep Heights, Pokhara, Nepal

Phone No. 00977-61-26630, Fax No. 00977-61-22160, e-mail Address :mcoms@mos.com.np 


\section{HISTORY:}

A 40 years old male presented with complaints of dull aching pain in the right lower abdomen for four years and loss of weight and appetite for six months. He gave a history of central abdominal pain, generalised abdominal distention, vomiting and constipation for the past four days. There was no history of haematemesis or malaena.

$\mathrm{He}$ is married for the past fifteen years, but has no children. He is a non-smoker and does not drink alcohol. He does not have diabetes, hypertension of ischaemic heart disease.

On examination the patient was moderately built and adequately nourished. He weighed $60 \mathrm{Kg}$ and was haemodynamically stable. General examination was normal. Secondary sexual characteris were well developed. There was generalised distention of the abdomen but no guarding or rigidity. On auscultation bowel sounds were exaggerated. On examination of the genitalia, the patient had cryptorchidism. Rectal examination revealed metastatic nodes in the recto-vesical pouch. Other systems were normal.

\section{INVESTICATIONS:}

The Hb. was $11 \mathrm{gm} \%$, Random blood sugar $120 \mathrm{mg} \%$, creatinine $0.7 \mathrm{mg} \%$, sodium $143 \mathrm{meq} /$ $\mathrm{L}$ and potassium was $4.5 \mathrm{meq} / \mathrm{L}$. Chest X-ray and ECG were normal. Plain Xray abdomen in the erect position showed multiple airfluid levels while the supine film showed dilated loops of intestine with valvulae conniventes. Ultrasound abdomen showed no metastatic lesions in the liver.

\section{TREATMENT:}

The patient was prepared for surgery. At laparotomy distended loops of jejunum and ileum with annular stricture at the terminal ileum were found. Right hemicolectomy along with biopsies of mesenteric and pelvic lymph nodes were done. Atrophied right testis present near the Picture 2

Plain X-Ray Abdomen -Supine Position: Showing Dilated Loops of Intestine with valvulae Conniventes (Jejunum). deep inguinal ring was biopsied. The post-operative period was normal.

\section{BIOPSY REPORT:}

(Biopsy No. 885/98-Manipal College of

Medical Sciences, Pokhara, Nepal)

1. Carcinoid tumour of distal ileum with metastases to mesenteric and pelvic nodes.

2. Right undescended testis in a patient with cryptorchidism.

\section{GROSS FINDINGS:}

Specimen consists of part of small intestine, caecum, appendix, and part of large intestine measuring $34 \mathrm{~cm}$ in length. Cut surface shows an area of stricture. $18 \mathrm{~cm}$ from the proximal resected end (small bowel end) Cut surface through the area

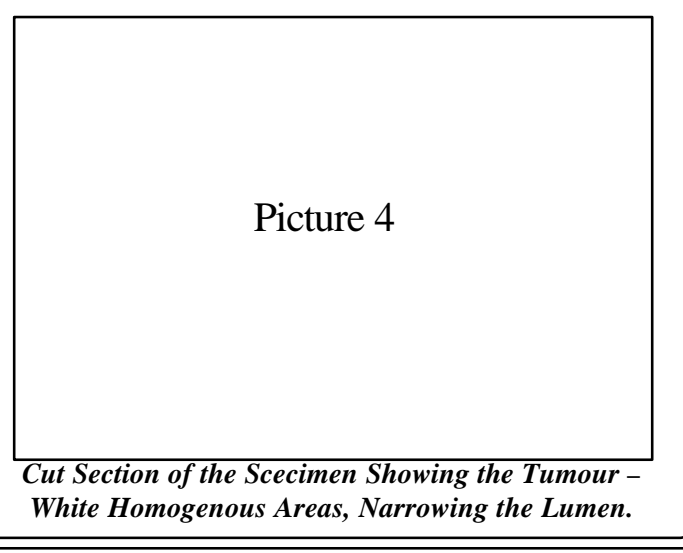

JNMA, January-March, 2000, 39 
shows narrowing of the lumen, areas of ulceration and a solid white area (the tumour), involving the entire thickness of the wall up to the serosa. Ulcer is excavated and measures $3 \times 3 \mathrm{cms}$.

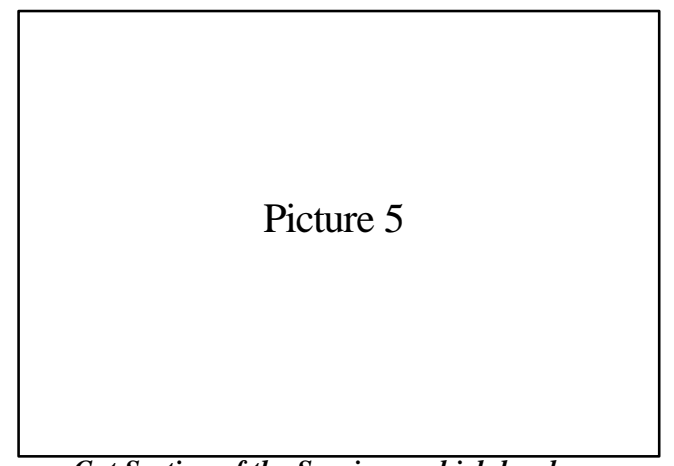

Cut Section of the Specimen which has been stretched out. Tumour Area shows Narrowing of the

Four lymph nodes are isolated in the mesentery. Cut surface of three lymph nodes show gray white areas. Another lymph node from the pelvis shows yellowish to brownish areas. Another bit of tissue measuring $0.5 \times 0.5 \mathrm{~cm}$ which has a homogenous cut surface.

\section{MICROSCOPIC FINDINGS:}

Sections show a tumour composed of tumour cells forming nests and ribbon pattern separated by thin fibrovascular connective tissue. Cells of the tumour show distinct cytoplasmic membrane with pale eosinophilic cytoplasm, vesicular nuclei,

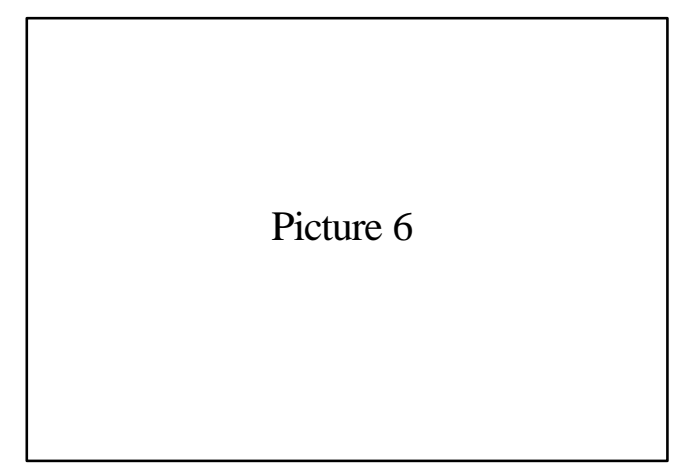

High Power view of the malignant carcinoid Tumour : shows malignant round cells.

coarse granular chromatin and tiny conspicuous nucleoli. Tumour cells are involving the full thickness or the wall of the bowel. Overlying mucosa is ulcerated.

Mesenteric lymph nodes show metastasis. Pelvic nodes also show metatasis. Another bit (bi- opsy from the atrophied right testis) which is received show presence of seminal vesicles.

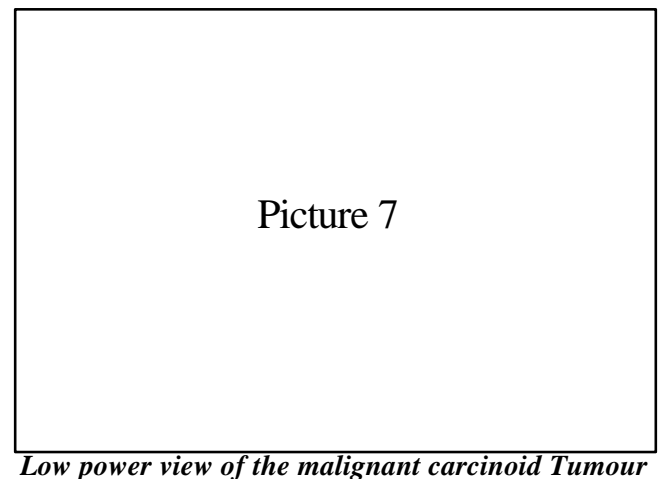

\section{DISCUSSION:}

The patient presented with acute intestinal obstruction for which exploratory laparotomy and right hemicolectomy was done. The tumour on biopsy was reported as carcinoid tumour of the distal ileum along with metastases to mesenteric and pelvic lymph nodes.

Doxorubicin is said to give a $20 \%$ tunour response rate ${ }^{10}$, while Octeotide is useful in controlling diarrhoea in patients having carcinoid syndrome. Some centres have used Interferon ${ }^{8}$ on an experimental basis.

In malignant carcinoid tumour greater than $2 \times 2 \mathrm{~cm}$ in size, the incidence of lymph node metastasis is greater than $66 \%$, whereas tumours less than $1 \mathrm{x} 1 \mathrm{~cm}$ have an incidence of $5 \%$ (lymph node metastases).

For tumours larger than $2 \mathrm{~cm}$ arising from the distal ileum, right hemicolectomy is the treatment of choice. ${ }^{9}$

At follow-up after three months the patient had gained 3 kilograms of weight. Repeat ultrasound showed no evidence of metastasis to the liver. So far there has been no case-report of a patient with carcinoid tumour having cryptorchidism.

\section{ACKNOWLEDGMENTS:}

1. Ms. Bimala Neupane for typing the manuscript

2. Namuna photo studio - Pokhara, for photographs of the specimen

3. Department of Pathology - Mangalore Medical College and Mr. Suresh for pictures of the photomicrographs (Slides).

JNMA, January-March, 2000, 39 


\section{REFERENCES:}

1. Haile T. Debas, Susan L. Orloff. Carcinoid tumours and the carcinoid syndrome. Sabiston textbook of Surgery $15^{\text {th }}$ edition $\mathrm{p} 950-954$

2. John GN Studley, Robin N Williamson. Hamartomas and benign neoplasms of the small intestine. Oxford textbook of surgery : Oxford Med. Publication, Vol. 1; p.1004-1006.

3. Cotran, Kumar, Robbins. Tumours of the gastrointestinal tract. Robbins pathological basis of diseases. $4^{\text {th }}$ Ed. WB Saunders international edition: p.872-875.

4. Salaja F. successful bronchoscopic stinting for a $15 \mathrm{~mm}$ sized bronchial carcinoid tumour Monaldi-Arch-Chest-Dis. 1995 Jan; 50 (1):16-7.

5. Dusmet M, McKnealy MF. Bronchial and thymic carcinoids tumours-a review. Digestion 1994; 55 suppl. 3:70-6.
6. El-Naggar AK, Troncoso $\mathrm{P}$ et al. Primary renal carcinoid tumours. Diagn. Mol. Pathol. 1995 March 4 (1), 48-53.

7. Monsaint H, Mikaelian JC at. Pure primary carcinoid tumours of the testis. Prog. Urol. 1995 Apr. 5 (2) 274-5

8. Makridis C, Juhlin C et al. MHC class I and II antigen expression and alpha treatment of human midgut carcinoid tumours World Journal of Surgery 1994 Jul-Aug 18 (4):481-6.

9. Rothmund M, Kisker O Surgical treatment of carcinoid tumours of the small bowel, appendix, colon and rectum. Digestion 1994; 55 suppl 3: $86-91$

10.JGM McDiarmid, J Bernard et al; GI and Hepatobiliary Pathology (MCQ's in Pathology for the FRCS). Arnold ISE 1997 Edition Chapter $4, \mathrm{P} 27$ 